\title{
A zero-dimensional view of atmospheric degradation of levoglucosan (LEVCHEM_v1) using numerical chamber simulations
}

\author{
Loredana G. Suciu' ${ }^{1}$, Robert J. Griffin² ${ }^{2}$ Caroline A. Masiello ${ }^{1,3}$ \\ ${ }^{1}$ Department of Earth, Environmental and Planetary Sciences, Rice University, Houston, 77005, USA \\ ${ }^{2}$ Departments of Civil and Environmental Engineering and Chemical and Biomolecular Engineering, Rice University, \\ Houston, 77005, USA \\ ${ }^{3}$ Departments of Chemistry and Biosciences, Rice University, Houston, 77005, USA \\ Correspondence to: Loredana G. Suciu (lgs4@ @ice.edu)
}

\section{Levoglucosan and the products of its chemical degradation}

The chemical structure of levoglucosan (LEV) and its gas-phase and aerosol-phase degradation products (LEVP\#) are shown in Figure S1. Products LEVP1, LEVP2, LEVP3 and LEVP5 are generated in both phases (gas and aerosol), product LEVP4 is generated only in the gas phase, and products LEVP6 and LEVP7 are generated only in the aerosol phase. However, because the last three products can partition between phases via either evaporation or condensation, they are also considered degradation products in both the aerosol and gas phase. Henceforth, in their respective chemical mechanism, they are labeled as LEVP\#_G or LEVP\#_A, in which letters G and A refer to gasphase and aerosol-phase, respectively. The chemical structures of LEV and LEVP1-LEVP4 are adapted from Bai et al. (2013) and those of LEVP6-LEVP7 are modeled with Chem3D 16.0, following the structures from Kessler et al. (2010). The chemical structure of LEVP5, also created with Chem3D 16.0, is introduced here for the first time based on the similarity of the reaction between an organic compound and $\mathrm{N}_{2} \mathrm{O}_{5}$ described by Gross et al. (2009). Intermediary or radical products are shown in Figure S2. The chemical structures of LEVR, LEVRO, LEVRO2 and LEVROOH are adapted from Bai et al. (2013), while that of LEVR1 is re-created using Chem3D 16.0, based on Kessler et al. (2010). Radicals are also common to both phases as they are generated by the phase-specific chemical mechanisms, but they are not considered in the G/P mechanism based on the assumption that they react very quickly once produced. 
LEV

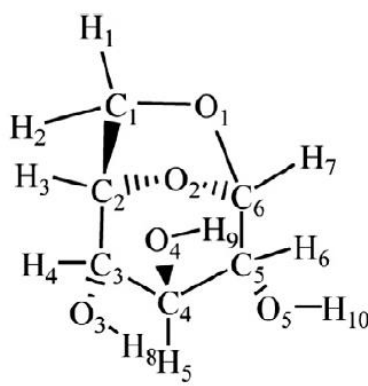

LEVP1

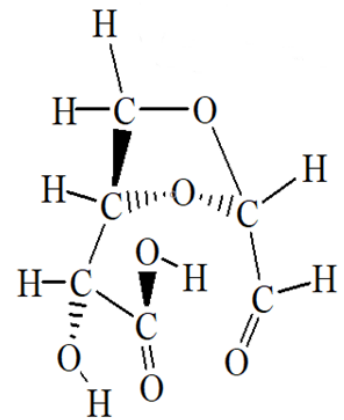

LEVP2

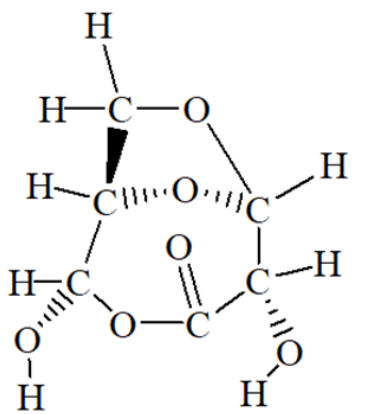

LEVP3

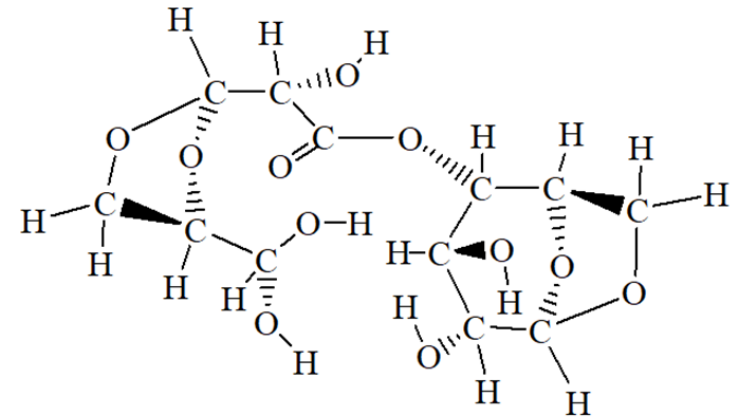

LEVP4

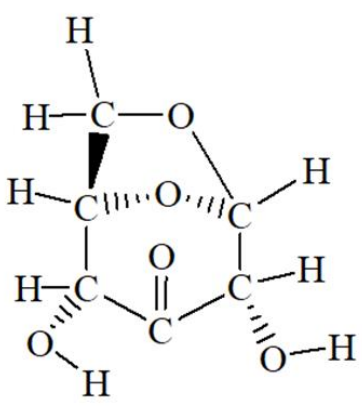

LEVP5

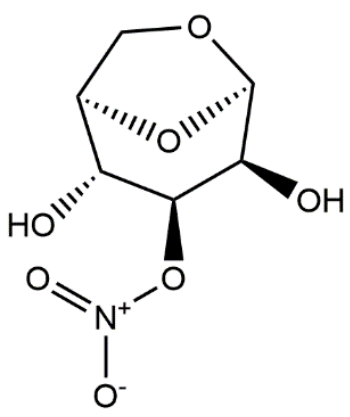

LEVP6<smiles>[R]C=O</smiles>

LEVP7<smiles>[R]C=O</smiles>

Figure S1: Chemical structures of levoglucosan and its degradation products 
LEVR

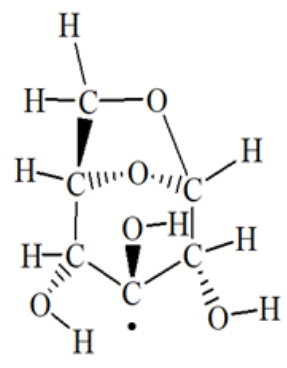

LEVROOH

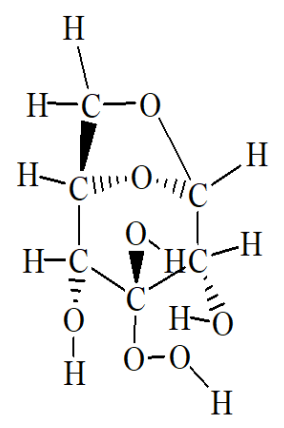

LEVR1

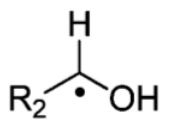

LEVRO

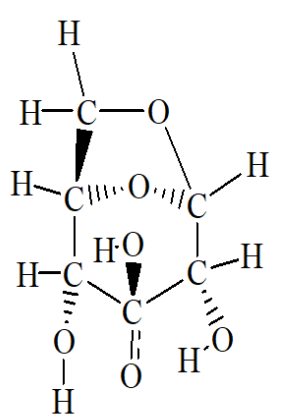

LEVRO2

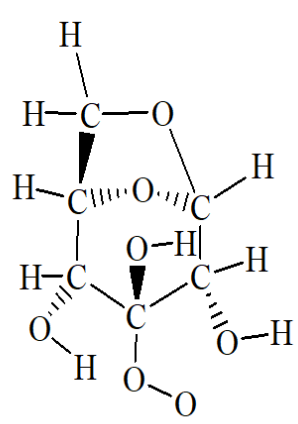

Figure S2: Chemical structures of intermediary (radical) products of levoglucosan degradation 


\section{Main conditions and parameters used in chamber simulations}

The initial conditions of LEV concentration in both phases and main parameters used in the chamber simulations are given in Table S1. Note that the BOXMOXv1.7 model used to develop LEVCHEM_v1 does not explicitly model relative humidity, but it does model $\mathrm{H}_{2} \mathrm{O}$ vapor concentration. Therefore, the values of $\mathrm{RH}$ used in chamber experiments were converted to $\mathrm{H}_{2} \mathrm{O}$ vapor concentration and used in the simulations to roughly reproduce the conditions used in chamber experiments from two studies (Hennigan et al., 2010; Lai et al., 2014). All simulations were conducted at ambient atmospheric pressure $(1013.35 \mathrm{hPa})$. Total aerosol number concentration $\left(\mathrm{N}_{\mathrm{t}}\right)$ and surface area density (SAD) were taken or calculated based on Seinfeld and Pandis (2006). Enthalpy of vaporization $\left(\Delta H_{v a p, i}\right)$ at $298.15 \mathrm{~K}$ was taken from Xie et al. (2014) and applied to all species (both LEV and its products) that were subjected to the gas-particle (G/P) partitioning mechanism. Surface tension $(\sigma)$ of LEV and related species was assumed to be similar to that of benzene and taken from Seinfeld and Pandis (2006). Saturation concentration of organics at $298 \mathrm{~K}\left(C_{i}^{*}(298 \mathrm{~K})\right.$ ) was taken from May et al. (2013). The bulk density of the particle ( $\rho$ ) was assumed to be the density of LEV. The diffusion coefficient for organic vapors in air (D) was taken from May et al. (2013) and assumed to be the same for all LEV-related species. 
Table S1 Conditions used in chamber simulations for model evaluation

\begin{tabular}{|c|c|c|c|c|c|c|c|c|c|c|c|c|c|}
\hline $\begin{array}{l}\text { Reference } \\
\text { study }\end{array}$ & $\begin{array}{l}\mathrm{LEV}_{-} \mathrm{G}_{0} \\
(\mathrm{ppmv})^{*}\end{array}$ & $\begin{array}{c}\text { LEV_A }_{0} \\
(\mathrm{ppmv})\end{array}$ & $\begin{array}{c}\mathrm{H}_{2} \mathrm{O} \\
\text { (ppmv) }\end{array}$ & $\begin{array}{l}\mathrm{RH} \\
(\%)\end{array}$ & $\begin{array}{c}T \\
(\mathrm{~K})\end{array}$ & $\begin{array}{l}\mathrm{D}_{\mathrm{p}} \\
(\mathrm{m})\end{array}$ & $\begin{array}{c}\mathrm{N}_{\mathrm{t}} \\
\left(\mathrm{m}^{-3}\right)\end{array}$ & $\begin{array}{l}\text { SAD } \\
\left(\mathrm{m}^{-1}\right)\end{array}$ & $\begin{array}{c}\Delta H_{\text {vap }, i} \\
\left(\mathrm{~J} \mathrm{~mol}^{-1}\right)\end{array}$ & $\begin{array}{c}\sigma \\
(\mathrm{N} / \mathrm{m})\end{array}$ & $\begin{array}{c}C_{i}^{*}(298 K) \\
\left(\mathrm{kg} \mathrm{m}^{3}\right)\end{array}$ & $\begin{array}{c}\rho \\
\left(\mathrm{kg} \mathrm{m}^{3}\right)\end{array}$ & $\begin{array}{c}\mathrm{D} \\
\left(\mathrm{m}^{2} \mathrm{~s}^{-1}\right)\end{array}$ \\
\hline $\begin{array}{l}\text { Hennigan } \\
\text { et al. } \\
\text { (2010) }\end{array}$ & $9.62 \times 10^{-2}$ & $6.23 \times 10^{-3}$ & $2.22 \times 10^{3}$ & 10 & 293.15 & $5 \times 10^{-7}$ & $3.18 \times 10^{7}$ & $2.50 \times 10^{-5}$ & $84 \times 10^{3}$ & $2.82 \times 10^{-2}$ & $3 \times 10^{-3}$ & $1.69 \times 10^{3}$ & $5 \times 10^{-6}$ \\
\hline Lai et al. & $9.62 \times 10^{-2}$ & $7.09 \times 10^{-4}$ & $1.18 \times 10^{4}$ & 40 & 298.15 & $2 \times 10^{-7}$ & $9.96 \times 10^{8}$ & $1.25 \times 10^{-4}$ & $84 \times 10^{3}$ & $2.82 \times 10^{-2}$ & $3 \times 10^{-3}$ & $1.69 \times 10^{3}$ & $5 \times 10^{-6}$ \\
\hline (2014) & $9.62 \times 10^{-2}$ & $7.09 \times 10^{-4}$ & $6.60 \times 10^{3}$ & 40 & 288.15 & $2 \times 10^{-7}$ & $9.96 \times 10^{8}$ & $1.25 \times 10^{-4}$ & $84 \times 10^{3}$ & $2.82 \times 10^{-2}$ & $3 \times 10^{-3}$ & $1.69 \times 10^{3}$ & $5 \times 10^{-6}$ \\
\hline
\end{tabular}

*The initial gas-phase LEV concentration was determined from its vapor pressure. 
3 Evolution of LEV degradation products and their relative importance
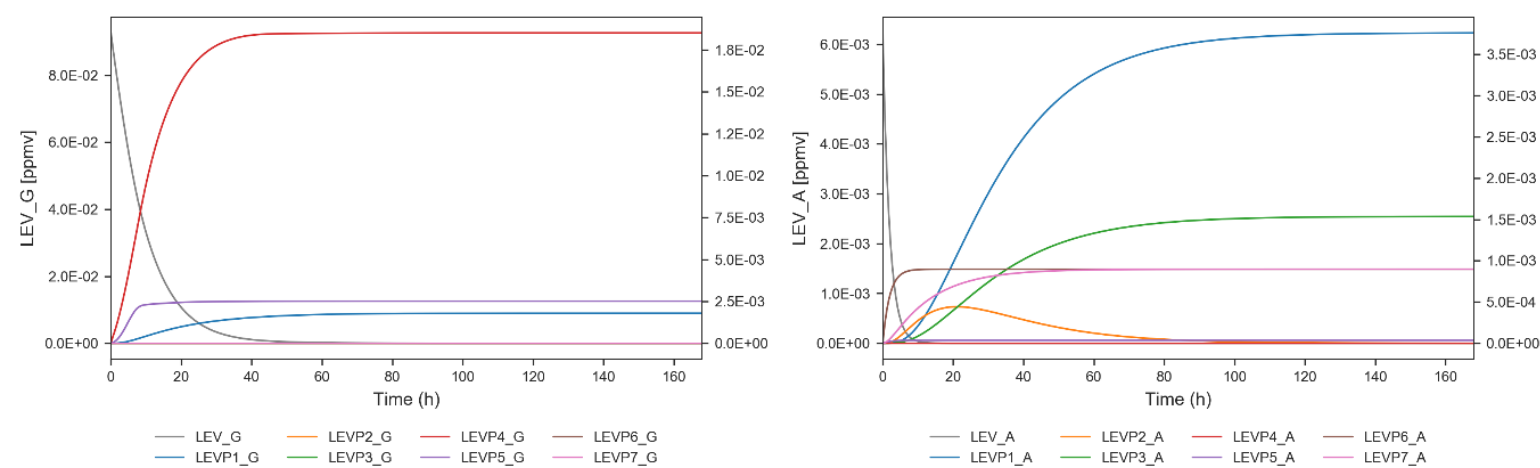

Figure S3: Products of LEV degradation in the gas phase (left) and the aerosol phase (right). $(F=0.02 ; \alpha=0.001)$ (simulated conditions based on Hennigan et al. (2010)). Concentration of products (ppmv) is displayed on the secondary y-axis.
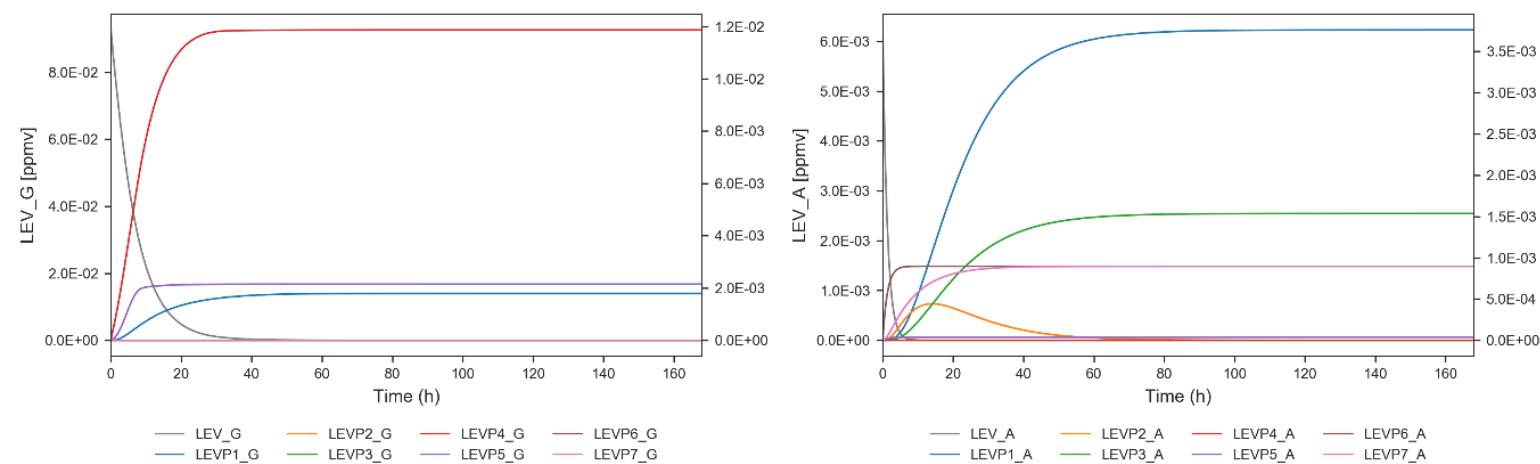

Figure S4: Products of LEV degradation in the gas phase (left) and the aerosol phase (right). $(F=0.03 ; \alpha=0.001)$ (simulated conditions based on Hennigan et al. (2010)). Concentration of products (ppmv) is displayed on the secondary y-axis.
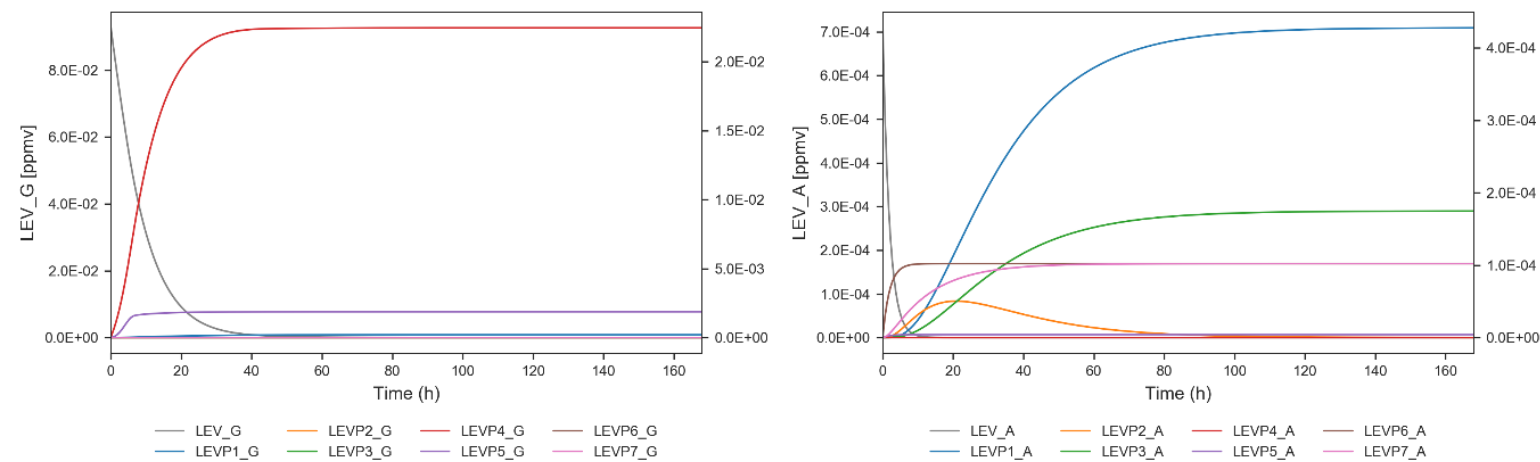

Figure S5: Products of LEV degradation in the gas phase (left) and the aerosol phase $($ right $) .(F=0.004 ; \alpha=0.001)$ (simulated conditions based on Lai et al. (2014)). Concentration of products (ppmv) is displayed on the secondary y-axis. 


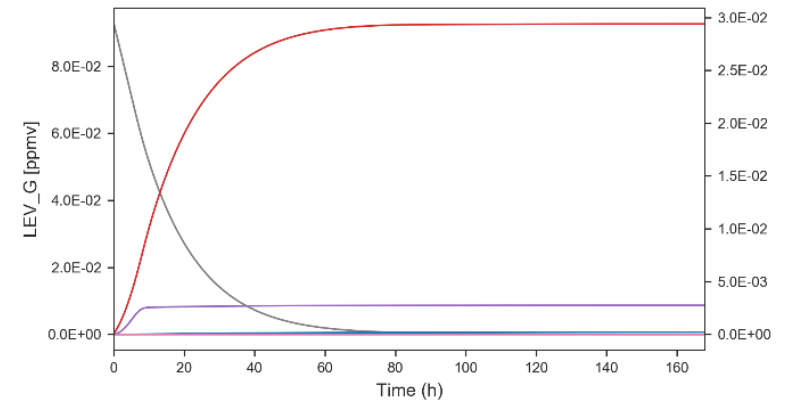

$\begin{array}{llll}\text { LEV_G } & \text { LeVP2_G } & \text { LEVP4_G } & \text { LEVP6_G } \\ \text { L LeVP1_G } & \text { LeVP3_G } & \text { LEVP5_G } & \text { LEVP7_G }\end{array}$

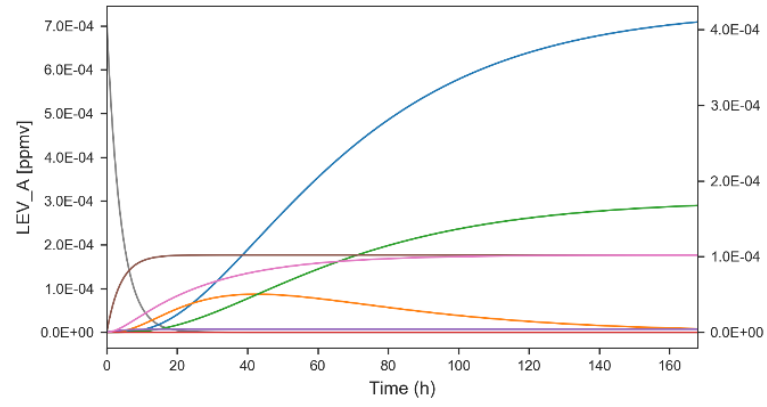

- LEV_A

Figure S6: Products of LEV degradation in the gas phase (left) and the aerosol phase (right). $(\mathrm{F}=0.002 ; \alpha=0.001)$ (simulated conditions based on Lai et al. (2014)). Concentration of products (ppmv) is displayed on the secondary $y$-axis.

\section{References}

Bai, J., Sun, X., Zhang, C., Xu, Y., Qi, C.: The OH-initiated atmospheric reaction mechanism and kinetics for levoglucosan emitted in biomass burning, Chemosphere, 93, 2004-2010, https://doi.org/10.1016/j.chemosphere.2013.07.021, 2013.

Gross, S., Ianonne, R., Xiao, S., Bertram, A. K.: Reactive uptake studies of NO3 and N2O5 on alkenoic acid, alkanoate, and polyalcohol substrates to probe nighttime aerosol chemistry, Phys. Chem. Chem. Phys., 11, 77927803, https://doi.org/10.1039/B904741G, 2009.

Hennigan, C.J., Sullivan, A. P., Collett, J. L., Robinson, A. L.: Levoglucosan stability in biomass burning particles exposed to hydroxyl radicals, Geophys. Res. Lett., 37, https://doi.org/10.1029/2010GL043088, 2010.

Kessler, S. H., Smith, J. D., Che, D. L., Worsnop, D. R., Wilson, K. R., Kroll, J. H.: Chemical sinks of organic aerosol: kinetics and products of the heterogeneous oxidation of erythritol and levoglucosan, Environ. Sci. Technol., 44, 7005-7010, https://doi.org/10.1021/es101465m, 2010.

Lai, C., Liu, Y., Ma, J., Ma, Q,. He, H.: Degradation kinetics of levoglucosan initiated by hydroxyl radical under different environmental conditions, Atmos. Environ., 91, 32-39, https://doi.org/10.1016/j.atmosenv.2014.03.054, 2014.

May, A. A., Levin, E. J. T., Hennigan, C. J., Riipinen, I., Lee, T., Collett, J. L., Jimenez, J. L., Kreidenweis, S. M., Robinson, A. L.: Gas-particle partitioning of primary organic aerosol emissions: 3. Biomass burning, J. Geophys. Res.- Atmos., 118, 11,327-11,338, https://doi.org/10.1002/jgrd.50828, 2013.

Seinfeld, J. H. and Pandis, S. N.: Atmospheric chemistry and physics: from air pollution to climate change, John Wiley \& Sons, Inc, Hoboken, NJ, 2006.

Xie, M., Hannigan, M. P., Barsanti, K. C.: Gas/particle partitioning of 2-methyltetrols and levoglucosan at an urban site in Denver, Environ Sci Technol, 48, 2835-2842, https://doi.org/10.1021/es405356n, 2014. 